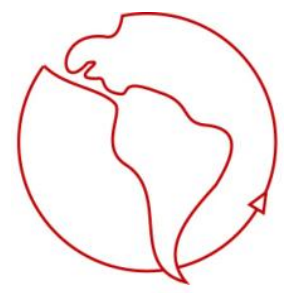

\title{
Políticas Educacionales en Chile durante el Siglo XX
}

Maximiliano Soto Sepúlveda

Magíster en Antropología y Desarrollo

maxiclio@hotmail.com

\section{Introducción}

Los proyectos modernizadores no deben cuestionarse o criticarse sólo desde el punto de vista bipolar, con una disputa permanente entre centro v/s periferia, ya que esta visión no nos permite entender, como señala el sociólogo Néstor García Canclini, el entretejido societal que se articula en cuanto a proyecciones oblicuas de poder, donde los lazos sociales no se pueden entender considerando solo dos puntos o referentes, ya que en la sociedades actuales se vive un multiculturalismo de carácter híbrido que entrelaza los gustos, los hábitos, las decisiones, las opiniones, y lo que más resalta, lo culto y lo popular, que habita en los ámbitos posmodernos, y que van conformando espacios de interés y de identificación: “...la modernización económica, política y tecnológica - nacida como parte de este proceso de secularización e independencia- fue configurando un tejido social envolvente, que subordina las fuerzas renovadoras y experimentales de la producción simbólica" (García 1995:32). Este planteamiento nos permite entender ciertos aportes que ha dado Chile en la Cultura, en niveles de exportación de industrias culturales, y además entender ciertas incoherencias en los intentos de impulsos que se han intentado construir durante el siglo XX, como por ejemplo el plan de industrialización de la Corfo, o el proyecto de reformas estructurales que se aplicaron durante el gobierno de Eduardo Frei Montalva. Han sido varios los intentos de coordinar una acción modernizadora, con un proyecto país, pero siempre se vuelve al mismo problema, en donde los proyectos socioeconómicos no marchan junto a un sentido de identificación sociocultural, según patrones de representación. García Canclini nos señala que hemos tenido diversas manifestaciones de modernización a lo largo del siglo XX, pensando en las oligarquías progresistas de principio de siglo, los procesos de alfabetización, la expansión del capitalismo, el ascenso democratizador de sectores medios y liberales, la difusión masiva de la escuela, la radio y la prensa, el proceso de industrialización de la década de 1940, el crecimiento urbano, el ascenso de la educación media y superior, y el surgimiento de nuevas industrias culturales. De hecho durante la primera mitad del siglo XX quedo en manifiesto un notable desarrollo cultural, considerando las producciones literarias de escritores como: Vicente Huidobro, Carlos Pessoa Véliz, entre otros; una expansión de áreas culturales diversas, en pintura resaltan las obras de Juan Francisco González y Onofre Jarpa, por lo tanto se manifestaron expresiones socioculturales de carácter nacional, que fueron expresiones del modernismo nacional, pero que no fueron a la par con las estrategias de modernización, debido a una diversificación recalcitrante de los procesos de democratización societal: "Como la modernización y democratización abarcan a una pequeña minoría, es imposible formar mercados simbólicos, donde puedan crecer campos culturales autónomos. Si ser culto en el sentido moderno es ante todo, ser letrado, en nuestro continente eso es imposible para más de la mitad de la población en 1920, esa restricción se acentuaba en las instancias superiores del sistema educativo, las que verdaderamente dan acceso a lo culto moderno" (García 1995:66-67). Manifestando una clara situación de exclusión social, donde las expresiones modernistas de la cultura estaban restringidas para un sector minoritario, a lo que el sociólogo chileno José Joaquín Brunner se suma: "El Chile de comienzos de siglo exige pertenecer a la clase dirigente para participar en los salones literarios, escribir en las revistas culturales y en los diarios. La hegemonía oligárquica se asienta en divisiones de la sociedad que limitan su expansión moderna" (García 1995: 67). Con lo cual queda en evidencia el sentido de contradicciones entre manifestaciones modernas de la sociedad a través de expresiones artísticas y literarias, por un lado, y proyectos modernizadores, como por ejemplo: La dictación de la Ley de Instrucción Primaria Obligatoria 
en 1920, y el Plan de gobierno de Arturo Alessandri Palma (1920-1925), como reflejos de políticas acordes con la necesidad de abrir nuevos espacios sociales, en un intento de inclusión de la marginalidad.

\section{El intento de inclusión de las oligarquías progresistas (1920): La ley de instrucción primaria obligatoria}

Durante este comienzo de siglo queda en evidencia que la modernización en Chile estaba presente pero en un mar de contradicciones fomentadas por las oligarquías imperantes, haciendo manifiestas las siguientes situaciones: Modernización con expansión restringida del Mercado, democratización para minorías, y renovación en las ideas pero con eficacia mínima en los procesos sociales, pese al pujante quehacer del movimiento obrero. Estas políticas modernizadoras son reflejo de contradicciones porque constatan una no aceptación de la cultura tradicional chilena, entendiendo como tradicional no el statu quo de la oligarquía progresista del principio de siglo, sino que las raíces identitarias del capital humano y cultural chileno, ligado a un pasado indígena, hispano, católico, urbano-rural, dependiente económicamente, y socialmente jerarquizado: "Los países latinoamericanos son actualmente resultado de la sedimentación, yuxtaposición y entrecruzamiento de tradiciones indígenas, del hispanismo colonial católico y de las acciones políticas, educativas y comunicacionales modernas. Pese a los intentos de dar a la cultura de élite un perfil moderno, recluyendo lo indígena y lo colonial en sectores populares, un mestizaje interclasista ha generado formaciones híbridas en todos los estratos sociales [...] Esta heterogeneidad multitemporal de la cultura moderna es consecuencia de una historia en la que la modernización operó pocas veces mediante la sustitución de lo tradicional y lo antiguo" (García 1995:71-72). De lo cual se puede derivar que las manifestaciones de un modernismo cultural eran sumamente limitadas para comienzos de siglo, pero lo que nos interesa presentar en este epígrafe esta relacionado con temas de la Ley de Instrucción Primaria Obligatoria que se dictó en 1920 durante el gobierno de Juan Luis Sanfuentes, donde se cimentaban las bases de un supuesto Estado Docente.

Antes de señalar contenedor de dicha Ley es necesario hacer una descripción general de las políticas estatales y de la sociedad dirigente de la época. Durante la primeras décadas del siglo XX se hubiese desarrollado un proyecto de alma colectiva dirigido por las élites oligárquicas de la época, dentro de un contexto de sistema parlamentario de gobierno, es decir desde un proyecto de gobernabilidad que para mantener la legitimación de su poder no deja abierta la puerta a la sociedad civil como agente proyectual de participación política. "Todo indica que en el tránsito del siglo XIX al XX la elite dirigente enfrentó una crisis de legitimidad y predominio político, y por extensión, pareció hacer posible un cambio de la sociedad en su conjunto" (Salazar-Pinto 1999:40); pero hacia la década de 1910 la percepción política, económica y social de la oligarquía chilena había cambiado: "Su balance económico era discutible como también lo era su débil $-\mathrm{o}$ case inexistente- iniciativa en materia de políticas sociales. [...] Paradójicamente, y tal vez fieles a su ya centenaria convicción de ser la clase política y activa del país por excelencia, extrapolaron su crisis al conjunto de la sociedad, y sintieron que era "el país" el que se deslizaba hacia el desastre" (Idem). Para este periodo se evidencia que la clase política dirigente no estaba preparada para asumir reformas estructurales que dieran paso a una modernización amplia y que incluyera a todos los sectores sociales presentes, como la reglamentación educacional (instrucción primaria) y de la "cuestión social" (contrato laboral, descanso dominical, seguro obrero, entre otras).

Por lo general cuando una clase políticas se acostumbra a la legitimidad del poder, se acostumbra a una posesión que no deja muchos canales o espacios a la modernización de sus estructuras de gobierno y de legitimidad. "La clase política pude, eventualmente, formarse en torno a grupos de interés privado, o por la auto-reproducción del poder político, pero también por la tendencia inercial de la máquina estatal a 'autonomizarse' y objetivarse, divorciándose de la masa ciudadana. En todos lo casos el final es el mismo: la formación de una 'minoría organizada que se instala en el poder y se lo transmite a sí misma. Como si 
fuera hereditario. Los ojos ciudadanos, entonces, ven que el estado se transfigura, de poder delegado en poder objetivado. De mandante en mandatario, de proyección ciudadana en "invasor del mundo de la vida" (Salazar-Pinto 1999:71). Fue precisamente esta objetivación del poder político por parte de las elites oligárquicas de principio de siglo lo que fue, en base a esta alma colectiva, trabando intentos de modernización societal.

A comienzos del siglo XX la documentación de la época refleja a una sociedad extremamente segmentada, que era producto de un sistema político que no había concretizado un cuerpo legal y educacional se promoción social. "Las condiciones de vida de los pobres en las ciudades eran terribles. Hacinándolos en grupos de hasta ocho personas en un solo cuarto sin ventilación (de cinco por ocho metros), los conventillos se habían convertido en fétidas incubadoras de enfermedades, sus habitantes morían de tuberculosis, enfermedades respiratorias o, en algunos casos, de simple asfixia. En 1906, el Congreso creó el Consejo de Habitaciones de Obreros para garantizar condiciones mínimas de seguridad en las viviendas existentes y, en caso de necesidad reemplazar los espacios no seguros. Dicho consejo nunca recibió la financiación adecuada". Esto refleja la precaria vida que llevaban las personas que del ámbito rural se trasladaban a la ciudad de santiago, una urbe que no tenía las condiciones de habitabilidad e higiene para constituirse como centro de promoción social, ya que reflejaba la jerarquización de la sociedad chilena en sí misma, como ciudad. A estas condiciones de hacinamiento se suman las precarias condiciones de higiene urbana: "Las enfermedades contagiosas abundaban: la viruela, la difteria, la tos convulsiva, la meningitis y las paperas diezmaban a los habitantes de las ciudades, tal como lo habían hecho el tifus. Las epidemias se habían convertido en una de las pocas fuerzas en la vida chilena que no hacían diferencia de clase. El cólera, la fiebre amarilla y la peste bubónica aniquilaron democráticamente a ricos y pobres por igual. Entre 1909 y 1914, más de 100.000 chilenos perecieron al año por enfermedad. La viruela por sí sola mató a 10.000 al año. Los hombres sucumbían en mayor número que las mujeres. Los niños de menos de un año constituían entre el $33 \%$ y el $40 \%$ de la tasas de mortalidad anual total, algunos por haber sido abandonados (25.000 tan sólo en Santiago entre 1870 y 1910); otros, por infanticidio" (Collier-Sater 1996:161).

A esta realidad cotidiana se suman algunos elementos objetivos de transformación social y económica durante las primeras décadas del siglo, referentes a infraestructura, urbanismo, e industrialismo. "En 1907, alrededor del $40 \%$ de todos los chilenos vivían en comunidades de más de 2.000 personas. La población de Santiago ese año alcanzó las 332.000 personas; la de Valparaíso, las 162.000; habían más de veintidós ciudades de más de 10.000 personas (en comparación con las seis de 1865)" (Collier-Sater 1996:160). Estas transformaciones urbanas hay que relacionarlas con es apogeo del salitre, ya que desde el pinto urbano se generara una expansión de los campamentos mineros en el norte salitrero, los cuales se dirigirán al Valle Central del país ocasionando una sobresaturación migratoria, al finalizar la época del salitre (a partir de 1920). Desde el punto de vista laboral durante este periodo se produce el auge de la clase media como sector emergente, desde donde se pueden visualizar ciertas transformaciones relacionadas con éste sector: "Los requerimientos del comercio internacional y las finanzas creaban un sinnúmero de nuevos puestos en las oficinas; la creciente burocracia fiscal (en 1919, había 27.000 empleados públicos, nueve veces más que en 1880), aumentaban las filas de la nueva clase social en ciernes -como lo hicieron los profesores de escuela, los periodistas y los oficiales de las fuerzas armadas" (Collier-Sater 1996:158-159).

Y desde esta perspectiva se puede visualizar una notable transformación en el campo educacional: "La educación fue un hueso duro de roer en estas discusiones: mientras los conservadores luchaban por mantener la independencia de las escuelas católicas, los anticlericales aspiraban con igual celo a que se implantar lo que ellos llamaban el 'Estado Docente' (La supervisión estatal de todo el sistema educativo). En parte, a esto se debe el extraordinario predominio del partido radical en la profesión pedagógica durante la primera mitad del siglo XX. Por lo mismo, la desconfianza de los conservadores fue una de las 
razones por las cuales el Congreso demoró tanto la legislación sobre la educación primaria obligatoria" (Collier-Sater 1996:173-174). Desde esta posición se puede hacer una primera lectura al proyecto de Ley de Instrucción primaria Obligatoria que se dictó en 1920, como un elemento fundamental en la consecutiva expansión de la clase media; para lo cuál era indispensable generar una transformación real y concreta en el sistema de educación primaria, como instrumento de promoción social. La oposición conservadora a este proyecto de ley se puede entender económicamente, ya que este sector representa un discurso desarrollista preindustrial sustentado en el latifundio y en la dependencia externa del sector exportador; y frente a esta situación la posición docente del estado era totalmente contraria a este discurso desarrollista.

Por lo tanto había una serie de elementos que condicionaban y ameritaban una necesaria estructuración de la educación primaria. Entre los factores externos se destacan la creciente toma de conciencia del estado de Chile, y la alta tasa de analfabetismo: "Más de 400.000 muchachos, pues, constituyen la reserva formidable del numeroso ejército de ineficaces con que cuenta nuestra población adulta. ¡Un millón y seiscientos mil analfabetos mayores de seis años! Colocados en fila, a cincuenta centímetros uno de otro, formarían una columna de 800 kilómetros de largo, la distancia que media entre Santiago y Puerto Montt. Si desfilaran frente al Congreso Nacional en hileras de a cuatro, a un metro de distancia una de otra, y marcharan a razón de cuarenta kilómetros por día, el ruido de sus pasos turbaría los oídos y la conciencia de nuestros legisladores durante diez días" (Salas 1917).

Como antecedente mediato a dicho proceso cabe señalar que en 1902 se celebra el Congreso General de Enseñanza Pública, donde se hizo notar la urgencia de atender a la dictación de una Ley de Instrucción Primaria Obligatoria. En 1904, la Asociación de Educación Nacional acuerda que luchará por la promulgación de una Ley de Educación Primaria Obligatoria. En 1910, el Congreso Científico, donde don Darío Salas, publica la obra "La Educación Primaria Obligatoria", donde formula la dictación de una ley que impusiera la obligatoriedad de la instrucción, corrigiendo lo que establecía el Código Civil por ser ésta incapaz de aplicarse. En 1917, los diputados radicales, en nombre de la Alianza Liberal, presentaron un nuevo proyecto de Ley de Instrucción Primaria Obligatoria, Gratuita y Laica. En 1918, los profesores formaron un Comité Central Pro Instrucción Primaria Obligatoria, constituido por representantes de instituciones políticas, gremiales, de la industria y el comercio y cuyo tenor era impulsar una campaña de aprobación de la Ley de, pues eran conscientes de que se trataba de un "problema de salvación nacional". Otro aspecto organizativo crucial en este proceso es la constitución de la Federación de Profesores de Instrucción Primaria el 5 de noviembre de 1918, para en 1919 realizar el Primer Congreso Educacional Primario.

Entre los factores internos que se planteaban en necesario destacar el sentido de gratuidad de la educación por parte del Estado y de las municipalidades lo que posibilitara la constitución del estado Docente; y una serie de teorías pedagógicas foráneas que contienen un sentido de modernización implícito de la educación, que intentan reestructurar el sistema pedagógico segmentado que se venía aplicando desde el siglo XIX, privilegiando a socialmente a las oligarquías dirigentes, modelo de carácter enciclopédico, verbalista y secularizado inspirado en la cultura francesa. Pero a fines de siglo, sobre este estilo pedagógico nos encontramos frente a le presencia de educadores europeos alemanes, quienes difundieron un nuevo modelo pedagógicos. Este nuevo modelo educativo y metodológico denominado herbatiano, constituye la primera reforma modernizante de la educación chilena, cuya pedagogía contenía fundamentos netamente científicos.

Dentro de las doctrinas pedagógicas, Herbart cimienta su sistema pedagógico a través de una metafísica esencialmente racionalista, sobre una psicología que reduce los sentimientos y la voluntad a productos secundarios de la razón. De él se deriva la tendencia psicológica de la educación moderna, es decir, la que 
establece que solamente sobre un estudio científico del espíritu infantil puede fundarse una doctrina pedagógica y formularse un proceso adecuado de instrucción. El planteamiento herbatiano plantea que la instrucción debe, ante todo, suministrar a los alumnos materias de representaciones que sirvan para formar conceptos lógicos claros y verdaderos. Herbart indujo la necesidad de que en la instrucción se estableciese desde temprano una concentración de materias afines para ser tratadas simultáneamente, y, a la vez, que en la presentación de cada una de ellas se hiciera surgir de bajo el umbral de la conciencia, aquellas nociones que sirvieran para reforzar a las que iban a ser materia de elección. Este sistema concéntrico, tendió a sustituir la enseñanza de materias aisladas e independientes unas de otras, por la enseñanza simultánea de varios ramos a la vez, que comienza con los conceptos básicos de cada uno de ellos y va haciéndose más complejos, de año en año, conforme a la maduración intelectual de los estudiantes.

Otra teoría pedagógica que se difundió dentro del perfil educativo de la ley de instrucción Primaria Obligatoria es la propuesta de Williams James, quien orientó la pedagogía de la época, cuyo sentido era que los profesores debían preocuparse de observar a sus educandos y a estudiarlos psicológicamente. Subrayó la importancia de los fenómenos emotivos y activos en el ejercicio de los hábitos y en la construcción del carácter, disminuyendo, por lo tanto, el énfasis colocado antes sobre los procesos puramente intelectuales. Sin embargo, pensamos que esta presencia no prendió en la práctica ni en el espíritu de los formadores, pues la rigidez de la práctica pedagógica se caracterizó por sus rasgos autoritarios y dogmáticos, donde el rigor disciplinario no excluía el castigo físico.

Pero la teoría pedagógica que más refleja el necesario espíritu de la modernización de la educación chilena en sus principios y prácticas la aporta John Dewey quien plantea la base de una teoría educacional, en el sentido de que es la escuela la que debe enseñar al hombre a vivir una existencia más armoniosa socialmente, más rica de significados, más de acuerdo con la evolución progresiva de la humanidad. Por lo tanto la educación la concibe como una función social, pues ésta es más necesaria a la colectividad que al individuo mismo, porque es ella la interesada en transmitir sus adquisiciones, sus normas y aun sus esperanzas a la generación venidera. Advierte que los conocimientos se adquieren por medio de la experiencia, es decir, de la relación vital entre el individuo y la cosa que se desea conocer, pero ésta debe experimentarse en función del medio, es decir, de ese contexto donde se insertan. Por lo tanto, la escuela fue concebida como el más significativo contexto de actividades vivas, en donde el niño, adquirirá una gran suma de experiencias y ocasiones para ejercitar aquellos impulsos suyos que son beneficiosos para el progreso social. Esta doctrina logra con este enfoque revolucionar los métodos, la disciplina, los programas, los locales y el mobiliario de los colegios que habían sido construidos para la transmisión oral de los conocimientos. La nueva educación debe apelar, en definitiva, a los instintos lúdicos o de juego, primero; a la actividad, siempre. Necesita el niño jugar, moverse, ejercitar sus músculos, sus manos, la agudeza de su visión, la fineza de todas sus percepciones, pues sólo en función de la actividad puede el niño desarrollarse. La enseñanza escolar, según Dewey "viene a ser la suma de procesos por medio de los cuales una sociedad transmite a los niños sus capacidades, adquisiciones e ideales, para asegura la supervivencia y progreso de esa sociedad" (Labarca 1927:69).

Respecto de las metodologías que se llevaban a cabo en las aulas, el aprendizaje se obtenía mediante una combinación de clases expositivas, de tareas frecuentemente mecánicas y de la memorización por efecto de la repetición de textos o de dictados del profesor. Se aprendía para evitar puniciones y/u obtener calificaciones. Los exámenes, por lo general, presidían la didáctica, desde los exámenes universitarios hasta el temido bachillerato y desde éste, al examen de fin de año que debían rendir los alumnos de la más remota escuela rural.

\section{La Educación como Política de Industrialización: El Discurso Educacional de Pedro Aguirre Cerda}


El periodo posterior a la dictación de la Ley de Instrucción Primaria Obligatoria, coincide con un periodo de cambio y de crisis, debido a las repercusiones de la Primera Guerra Mundial, a la crisis económica mundial de 1929 (el jueves negro) e internamente a la ascensión de los grupos medios en el gobierno de Arturo Alessandri Palma (1920-1925), y a su consecutiva presión social, y a la concreción de legislación social; en lo económico se comienza a estructurar un modelo de integración económica hacia adentro, y se adoptan consejos recomendados por la misión Kemmerer, con lo cual se intenta ordenan las finanzas nacionales mediante la estructuración del Banco Central (1925); una serie de cambios que van acorde con la dictación de una nueva Constitución Política que pretende devolver la dirigencia del gobierno al presidente mediante atribuciones extraordinarias. Este periodo crítico "ha tendido a trabajar la unidad a partir de "procesos inductivos" fundados en algún tipo de "consenso". Asumiendo la unidad, de hecho, como una tarea o construcción histórica. Subentendiendo que la realidad es, ante todo, un producto social. La progresiva consolidación de esta tendencia debilitó, consiguientemente, el rol de los 'grandes hombres'. Los 'caudillos' chilenos, después de 1938, se hallaron, por ello, enfrentados a un doble e inevitable modo de subordinar su genialidad: o bien a los 'consensos tecnocráticos, o bien de los 'consensos ciudadanos' que, como marea, presionaban desde abajo" (Salazar-Pinto 1999:127). En este sentido para 1930 la hegemonía de las clases de productores fue sustituida por una alianza tecnocráticanacional formada por los ingenieros civiles y por la nueva generación de políticos científicos, como le caso de Pedro Aguirre Cerda. Para este periodo ya se proyectaba el rol de un Estado empresarial o fabril, lo que iba acorde con una eminente transformación social: "El triunfo de los frentes populares significó un reemplazó de los partidos políticos oligárquicos en el gobierno por nuevos personajes y grupos profesionales y técnicos (e ideológicos), que pertenecían en muchos casos a las capas medias y abrigaban los ideales desarrollistas y mesocráticos de los años treinta a los cuarenta. Sin embargo, al hablar de la constitución de los grupos o clases dominantes específicamente para este periodo, puede caerse en la desviación de juzgar la estructura global del poder de las clases dominantes sólo por su incidencia en lo político" (Salazar-Pinto 1999:41). Desde donde podemos entender la evolución político-social de un alma colectiva hacia un alma inducida, desde un proyecto de integración hacia afuera, a un proyecto de integración hacia adentro; una serie de aspectos socioeconómicos que se pueden evidenciar en esta nueva burguesía industrial que logra integrarse en los discursos presidenciales. "Las nuevas burguesías industriales y comerciales que se integran a partir del ocaso del gobierno oligárquico tradicional acusan el aire de los tiempos. El modelo parisino ya no es más que un recuerdo del pasado. Sus esposas y sus hijas ya no son damas caritativas, vestidas d negro y dedicadas a las labores piadosas; la beneficencia es principalmente asunto del Estado [...]. Los "modos de ser" de la elite decimonónica ... ya no son hegemónicos" (Salazar-Pinto 1999:42). La reestructuración política de gobierno basada en la estrategia de frente popular, refleja este alzamiento de los grupos medios emergentes en alianza con los sectores populares: "Personajes venidos de los grupos medios y de los inmigrantes -elevados por el éxito económico o el talento personal- surgen junto a las elites sociales tradicionales. Los radicales, desde este punto de vista, conformaron una elite de modos de ser y gobernar diferente a la clase alta tradicional. Se identificaron con la tradición laica y proeducacionista propia de los sectores medios profesionales, que habían ganado fuerte respetabilidad" (Salazar-Pinto 1999:43). Y es precisamente de esta tradición laica y proeducacionista que se reestructura la educación en Chile como pilar fundamental de la transformación económica nacional, asumiendo el estado u rol económico sustentado en impulsar un proceso de industrialización que lograra un cierto equilibrio en la sociedad segmentada de la época.

Frente a esta transformación de la sociedad era de vital importancia reestructurar los planes educacionales que se estaban aplicado. Para de esta manera constituir uno de los pilares fundamental en esta nueva política proeducacionista, la educación técnica, y hacer frente a las contradicciones entre modernización y sociedad, lo que durante los primeros gobiernos radicales de Pedro Aguirre cerda y Juan Antonio Ríos se ve sujeto a ciertos cambios. Durante este periodo las ciudades experimentan una transformación ligada a la industrialización y a los procesos de crecimiento y urbanización, producto del despegue de un 
desarrollo económico más sostenido y diversificado, que tiene su base en el crecimiento de industrias con tecnología avanzada, sumado a un aumento de importaciones industriales y de empleos asalariados, con lo cual se consolida y expande el crecimiento urbano. Dentro de esta época de transformación podemos situar ciertos fenómenos de transformación estructural de la sociedad chilena y de la educación: El plan ISI de los gobiernos radicales, en donde se pretende sustituir la importaciones por la industrialización, con lo cual el Estado asumía el papel de gran gestor en la transformación económica del país, periodo durante el cual nace la Corfo; y la aplicación del discurso presidencial: Gobernar es educar, ampliándose la educación técnica del país (a nivel secundario y superior).

Además de esta transformaciones sociales, económicas y políticas, es necesario señalar las transformaciones urbanas que se experimentaron durante este periodo, ya que permite tener una visión amplia de los procesos de urbanización ligados a un cambio macro societal de la estructura nacional. "La explosión demográfica de Santiago se debió no sólo al aumento natural de la población, sino también a la migración al interior del país, ya que miles de chilenos dejaron las haciendas o minifundios buscando trabajo en la gran ciudad. La contracción de la fuerza laboral de la Gran Minería también se sumo a lo anterior: 54.000 norteños se unieron a la marea que llegó a la capital entre la década de 1930 y 1952 . Si antes Santiago dominaba la vida de la nación, ahora lo hacía en forma más absoluta que nunca" (CollierSater 1996:253). Frente a estos cambios sociales y urbanos, sumandos a una necesaria reestructuración de la economía nacional, para contrarrestar las repercusiones de macro-dependencia sufridos en la década anterior, la aplicación del discurso presidencial de Pedro Aguirre Cerda era crucial: Gobernar es Educar.

Y fue de esta manera que se fue estructurando una profunda red de cambio a nivel Técnico, se hablaba de la nueva escuela como pilar de modernización social. Entre los principales puntos que planteaba en su discurso presidencial referente a la educación podemos situar los siguientes: i) Reforma educacional en armonía con los intereses de la sociedad, incluida la educación de adultos y las escuelas complementarias. ii) Continuidad de la educación hasta la Universidad. iii) Gratuidad de la enseñanza en todos sus grados. iv) La Educación Primaria, Secundaria y Técnica debe ser función del estado o, a lo menos, controlada por él. v) Creación de Institutos y universidades de Trabajo. vi) Protección del Estado y de los municipios a los escolares indigentes; alimentación, vestuario, útiles y atención sanitaria. vii) El maestro no puede ser perseguido por sus ideas políticas (Recio.2001:49). Lo que visualizaba a la educación como un ingrediente indispensable a la hora de plantear un modelo global de desarrollo.

Pero en la práctica durante su gobierno convivieron dos modelos educacionales. La educación tradicional sustentada en el asignaturismo y enciclopedismo correspondiente al campo de acción de las elites oligárquicas; y la educación experimental que descansaba en la pedagogía pragmática de John Dewey, planteando que las disciplinas son instrumentos de análisis, y no un fin en sí mismas; y que la finalidad de la educación es desarrollar la capacidad para las soluciones de problemas de la vida democrática. Esta situación evidencia que el intento de modernización de la educación en Chile choco durante este periodo con estructuras arcaicas y segmentadas del modo de ser de las clases sociales en Chile: "...se podría decir que el país desarrolló un sistema educativo paralelo. Las familias ricas (y muchas de la clase media alta) mandaban a sus hijos a colegios privados: en las décadas de 1940 y 1950, respectivamente, un $28 \%$ y un $35 \%$ de los niños en edad escolar iban a colegios de primaria y secundaria privados. A nivel secundario, los colegios privados eran más numerosos (122 en 1945, 453 en 1956) que los liceos estatales, aunque tenían menos alumnos" (Collier-Sater 1996:252). Pero de igual forma el plan educacional de los gobierno radicales iba a tener sus frutos, "la escuela nueva" logro desarrollar vocaciones acordes con la política de industrialización del gobierno, para lo cual creó la Facultad de Comercio y Economía Industrial de la Universidad de Chile, con el fin de capacitar a los sujetos para enfrentar el desafío industrial. Dentro de este mismo contexto la Universidad de Chile se transformó en un importante centro de investigación científica. Un discurso que también se aplicó en los sectores populares al crearse el Instituto de Inquilinos, 
una iniciativa que fue apoyada con la creación de numerosas escuelas rurales con el fin de iniciar un vasto plan de alfabetización, de mejorar los niveles de instrucción en los campesinos, y de capacitarlos para aumentar la producción agrícola y de elevar sus condiciones de vida. También se fundaron escuelas de artesanos e industriales en casi todas las provincias, y escuelas femeninas; con el fin de aumentar los niveles de participación y de inclusión social y cívica de este sector tan postergado. Toda una labor de estructuración educacional que alcanzaría su mayor logró en la educación superior con la fundación de la Universidad Técnica del Estado en 1947.

\section{La Educación como Pilar de Reestructuración Social: La Revolución en Libertad de Eduardo Frei Montalva}

A comienzos de la década de 1960 pese a un crecimiento sostenido de la población escolar, se seguían visualizando problemas de carácter estructural: La dificultad de acceso del nivel primario al secundario y superior, y la aplicación de programas educacionales desvinculados de la realidad nacional; para una población que en 1964 ascendía a la suma de 8 millones.

Desde los gobiernos radicales el Estado, en su rol empresarial, había asumido la educación como una de sus primeras tareas, y que económicamente concentraba con creces el gasto público gubernamental, asumiendo esta área como un pilar fundamental dentro del modelo desarrollista en pro de la industrialización, pero que durante la década de 1950 se vio debilitado y disminuido la prioridad de inversión en esta área : "Hasta 1925, la educación había absorbido casi todos los gastos 'sociales' del gobierno. En 1955, la educación sólo recibía un 20,3\% del gasto público social; la vivienda y las obras públicas, el 20,4\%. El programa de seguridad social, que constituía el 41,4\% y el 51,4\% del gasto público en 1955 y e 1961, respectivamente, se convirtió en el capítulo más caro del presupuesto". (Collier-Sater 1996:251). Índices que reflejan que la preocupación educacional por parte del estado no estaba apoyada con políticas de inversión gubernamental, y por otro lado tampoco reflejan un nivel de vida alto y acomodado para las personas que vivían en al ciudad, evidenciándose serios problemas alimenticios y nutricionales en la población. "En la provincia de Santiago, la más rica del país, el $60 \%$ de la población sufría de desnutrición entre 1968 y 1969. En este periodo, sólo la mitad de todas las familias de Chile consumían 1.600 calorías diarias, mientras que alrededor de un $25 \%$ tenían una ingesta diaria de 2.500 calorías" (Collier-Sater 1996:251).

Económicamente ya estaba bastante dinamizado el sistema de integración hacia adentro, con la aplicación del discurso desarrollista industrial sustentado en la ingeniería industrial dirigida por el estado como agente impulsor. Entre 1950 y 1968 el desarrollismo económico impulsado por la CEPAL destrono al libremercadismo del Fondo Monetario Internacional, lo que posibilito una interpretación nacional del desarrollo económico, y a la vez una serie de reformas estructurales como la Reforma Agraria y la reforma Educacional durante los gobiernos de la década de 1960. "Desde 1930, el libremercadismo se quedó, prácticamente sin gente. El social-productivismo conquistaba todos los corazones, incluso dentro de la derecha política, donde los discursos del nacionalismo espiritual o el corporativismo social (dominante en los propios gremios patronales) hicieron olvidar el discurso de integración hacia afuera. Se produjo un olvido casi total de los principios básicos del mercado, sobre todo respecto a cómo tratar el "rebelde flagelo de la inflación". Los ingenieros de la CORFO, los economistas de la CEPAL y los sociólogos de DESAL asumieron la inflación como una herramienta heterodoxa para el desarrollo, ya que estimulaba la expansión de los negocios" (Salazar-Pinto 1999:169-170). Es dentro de este contexto de políticas económicas que se aplica el discurso de revolución en Libertad de Eduardo Frei Montalva, asumiendo en su discurso desarrollista industrial la promoción popular como estrategia de desarrollo y de integración hacia adentro, donde la Reforma Educacional y la reforma Agraria jugaban un papel fundamental. 
Para diagnosticar los problemas estructurales de la población escolar como el analfabetismo se constituyo una Comisión de Planeamiento Integral de la Educación Chilena que elaboró entre los años 1962 y 1964 un Informe que verificaba lo siguiente: La deserción escolar en la enseñanza primaria era de un 68\%; más del $30 \%$ de los licenciados del primer ciclo no accedían a la enseñanza media y la deserción en ésta era aproximadamente de un $75 \%$. El nivel educativo de la población chilena era de 4,2 años de estudios, siendo en la población rural de 2,4\% años. Fue así como en 1965 se inició la Reforma Educacional que tenía como objetivo central posibilitar el acceso igualitario al sistema educacional, y que la permanencia en él no dependiera de la situación económica del alumno; y además se ponderaba, como segundo gran objetivo, la integración de los alumnos a la comunidad y a las necesidades del desarrollo nacional a través de la educación que preparara para el trabajo, abriendo espacios a la participación y a la creatividad por parte de los alumnos.

Esta Reforma se estructuraba en los siguientes puntos: La extensión de la educación Primaria a ocho años; la aplicación de un modelo educativo como estrategia general del cambio social, con el fin de formar recursos humanos; y la aplicación de un nuevo modelo pedagógico sustentado en un cambio de orientaciones de contenidos a habilidades, en una reacción contra el enciclopedismo, y, finalmente, en un cambio de giro del profesor docente al profesor facilitador de la enseñanza. Esta reestructuración de la educación significo una modernización y un mejoramiento de las prácticas escolares, y además de una adecuación del desarrollo educacional a los cambios económicos-políticos-sociales que se estaban efectuando en Chile. "El esfuerzo por fomentar la educación fue notable: en términos de su porcentaje dentro del gasto Público, la educación subió de un $15 \%$ a un $20 \%$ [...]. Se construyeron algo así como 3.000 nuevos colegios: en 1970, la educación primaria cubría el 95\% de los niños en edad escolar. Se introdujeron una serie de nuevos textos de estudios muy creativos" (Collier-Sater 1996:270). Los alumnos de enseñanza media aumentaron de 139.200 en 1964, a 332.000 en 1967, lo que significó una tasa de crecimiento anual superior al 20\%. La enseñanza técnico-profesional también creció del $25 \%$ de la educación media que representaba en 1964, al 32\% en 1970. Y el objetivo de permanencia de alumnos en el sistema escolar se hizo posible gracias a la gestión de la Junta nacional de Auxilio Escolar y Becas.

Durante este periodo se pretendió coordinar desde le Estado las transformaciones estructurales de la sociedad a partir de los procesos de alfabetización, industrialización, y urbanización, se logró pero sin dar una consolidación coherente entre la modernización y la inclusión social, ya que los proyectos modernizadores de la educación se enmarcan dentro de un concepto coyuntural y no proyectual, lo que genera un permanente conflicto, tanto explícito como implícito entre el estado y la sociedad civil: "Lo culto paso a ser un área cultivada por fracciones de la burguesía y de los sectores medios, mientras la mayor parte de las clases altas y medias, y la casi totalidad de las clases populares, iban siendo adscritas a la programación masiva de la industria cultural" (García 1995:85). Este es el ambiente en el cual se asientan los proyectos modernizadores de la educación chilena, pero desde la década de 1970 hasta ahora la sociedad chilena ha ido sufriendo ciertos cambios estructurales que han acrecentado su hibridismo sociocultural, influenciado por tres condicionantes: El modelo neoliberalista de mercado, aplicado en Chile desde 1976; la expansión de la cultura Urbana; y las consecuencias comunicacionales de las nuevas tecnologías.

A este proceso de cambio hay que agregar la expansión de nuevas tecnologías comunicacionales a partir de las décadas de 1960 y 1970, las que contribuyen a una masificación e internacionalización de las relaciones culturales, lo que se evidencia con la Televisión .Si bien durante la primera mitad del siglo XX la sociedad chilena se articulaba contradictoriamente entre círculos de poder y presión social, lo que se intento coordinar en base a políticas modernizadoras, como las de los presidente Aguirre Cerda y Frei Montalva, desde la ciudad como agente público de articulación(cuatro de cada diez chilenos profesionales, técnicos y ejecutivos vivían y trabajaban en la capital, al igual que más de la mitad de las secretarias y los 
empleados de la nación). Durante la segunda mitad del siglo XX se produce un cambio o traslado del espacio público de participación visualizado en la urbe como lugar o dimensión de apropiación identitaria, lo que se incrementa con la Televisión como estrategia comunicacional: "El uso masivo de la ciudad para la teatralización política se reduce; las medidas económicas y los pedidos de colaboración al pueblo se anuncian por Televisión. Las marchas, los actos en calles y plazas, son ocasionales; o tienen menor eficacia" (García 1995:267). A esto nos referimos cuando planteamos que la ciudad ha cambiado como espacio público de articulación identitaria, es decir las personas han perdido espacios de identificación, trasladando espacios públicos de manifestación al hogar mediante la Televisión; lo que ve evidencia en una identificación con imágenes electrónicas y no vivencialidades dentro de la urbe. "Las identidades colectivas encuentran cada vez menos en la ciudad y en su historia, lejana o reciente, su escenario constitutivo. La información sobre las peripecias sociales se percibe en la casa, se comenta en la familia o con amigos cercanos. Casi toda la sociabilidad, y la reflexión sobre ella, se concentran en intercambios íntimos. Como la información de los aumentos de precios, lo que hizo el gobernante y hasta los accidentes del día anterior en nuestra propia ciudad nos llegan por los medios, éstos se vuelven los constituyentes dominantes del sentido público de la ciudad, los que simulan integrar un imaginario urbano desintegrador" (García 1995:268). Por lo tanto el espacio público de la política se configura en base a imágenes electrónicas que llevan a una disminución del interactuar entre el individuo y la urbe, generando un grado creciente de falta de identificación o vínculo entre el Yo-individuo y el Otro, entorno, es decir se fragmenta la identidad por pertenencia, por sentirse parte de un territorio definido y definible a la vez: “...una identidad que registra como importante la relación nutricia del hombre con el cosmos entendido como un complejo plan creador de diversidad" (Sepúlveda 2001:12); y que a la vez transforma al individuo en persona como una entidad espiritual y racional a la vez, integra en tiempo y espacio, y no dispersa, fragmentada o atomizada en un lugar particular.

\section{Reforma Educacional: Un Proyecto Reafirmado y Discutido}

Es desde las transformaciones que se han ido experimentando en Chile en los últimos treinta años donde hay que analizar la aplicación de la Reforma Educacional, visualizando sus aristas positivas y negativas, sin perder de vista las variables externas en su aplicación a partir de la década de 1990, periodo que se inserta dentro de los que muchos sociólogos denominan Posmodernidad o época postindustrial para aquella sociedades industrializadas, pero que en el caso de Latinoamérica la aplicación de este concepto es cuestionada. Pese a esta objeción hay que dejar claro que las relaciones sociales entre la persona y su entorno se ha transformado radicalmente en los últimos años, afectando las relaciones personales, familiares, comerciales, políticas, laborales, educacionales, y culturales: "Ser culto en una ciudad moderna consiste en saber distinguir entre lo que se compra para usar, lo que se rememora y lo que se goza simbólicamente. Requiere vivir en forma compartimentada el sistema social [...] Sin embargo, la vida urbana transgrede a cada momento este orden. En el movimiento de la ciudad los intereses mercantiles se cruzan con los históricos, los estéticos y los comunicacionales. Las luchas semánticas por neutralizarse, perturban el mensaje de los otros o cambian su significado, y subordinan a los demás a la propia lógica, son puestas en escena de los conflictos entre las fuerzas sociales: entre el mercado, la historia, el estado, la publicidad, y la lucha popular por sobrevivir" (García 1995:280). Son estos los cambios estructurales que se siguen autoreproduciendo fomentando la fragmentación social.

A esta situación de "transgresión simbólica" se suma una reestructuración de la clase política, que en Chile recuperó su rol hegemónico para insertar a Chile en el contexto internacional de la globalización, mediante estrategias de modernización diversas, que no necesariamente incluirían una injerencia y participación decisiva de la sociedad civil; como lo plantea el Informe de la Comisión Nacional para la Modernización de la Educación. "La clase política puede, eventualmente, formarse en torno a los núcleos de interés privado, o por la auto-reproducción del poder político, pero también por la tendencia inercial de 
la máquina estatal a 'autonomizarse' y objetivarse, divorciándose de la masa ciudadana”, de lo cual surge una minoría organizada que objetiviza los proyectos de gobierno con un intento de modernización pero que fragmenta en forma paulatina y constante la identidad del ethos societal, desvinculando los hábitos del modo de ser ciudadano en pro de las políticas tecnocráticas: "Los ojos ciudadanos, entonces, ven que el Estado se transfigura, de poder delegado en poder objetivado" (Salazar-Pinto 1999:71).

Durante la década del 70' se genera un giro en los proyectos económicos dejando de lado la estrategia desarrollista de integración hacia adentro articulada desde el Estado, para pasar a otra estrategia de integración hacia fuera sustentada en el libremercadismo articulado por el Mercado; lo que corresponde a la implantación de un plan de carácter neoliberal que echara por la borda ciertos proyectos de promoción social como la Reforma Agraria y la Reforma Educacional, fomentadas por los gobiernos de la década de 1960 en Chile. Esta implementación al no tener una base social orgánica de apoyo por la sociedad civil, se vuelve estratégicamente necesario y coyunturalmente urgente convocar a los militares, provocarlos y centrarlos en el estado reconociéndolos de paso como una salvadora clase política; por lo tanto la implementación del modelo neoliberal coincide plenamente con la aplicación de un Estado fuerte y centralizador.

Este periodo refleja una clara transformación de las elites de gobierno, quienes recuperaran su rol de liderazgo hegemónico, para desplazar al Estado como agente impulsor de la gestión pública. "...la masividad y persistencia del discurso anti-estatista procedente de los sectores de elite durante los últimos 25 años denotan una clara convicción de haber recuperado la iniciativa y estar en condiciones de ejercer su liderazgo sin necesidades de agentes intermediarios" (Salazar-Pinto 1999:58).Y es precisamente desde esta nueva estructuración tecnocrática de gobierno que se comienzan a entretejer redes de conexión entre la diversidades culturales, para aumentar la participación y los niveles de inclusión social dentro de la globalización industrial y comunicacional, lo que generara una serie de proyectos de legitimación societal desde la gobernabilidad sin hacer participar a la sociedad civil en la direccionalidad de los nuevos proyectos. "La diferencia en las conductas exhibidas y los valores defendidos; el aparente distanciamiento respecto del Estado y aún del propio pasado histórico; el recurso a formulas nuevas de legitimación (la "globalización", la eficiencia, el individualismo competitivo, el éxito material); incluso las fracturas que se perciben en torno a materias de orden "cultural"(el rol de la Iglesia o la familia, la "libertad de elegir" aplicada a situaciones de la vida privada); todo ello sugiere un cambio tan profundo en el ser social que algunos hasta postulan la sustitución de los grupos tradicionales de elite por una nueva tecnocracia empresarial, constituida originariamente bajo el alero del periodo dictatorial" (Salazar-Pinto 1999:59). Este cambio en el ser social apunta a una profundización de los procesos de individualización societal, lo que se comienza a articular al momento de insertar este modelo de modernización.

Estos procesos tienen el objetivo de fragmentar las identidades en esta sociedad desregulada nacional, desde estos nuevos mecanismos de expansión e integración económica hacia fuera: “...a las prácticas comunales de 'libertad participativa' (sujetas a responsabilidades cívicas), el comercio opuso, en sus ferias de suburbio, la 'libertad vivencial' (basada en la sensorialidad individual), y a la identidad comunal, la identidad de 'lo exótico'. Por esto, desde el principio, el libremercadismo ha proclamado la filosofía de las libertades individuales, cuya seducción sensorialista ha provocado un quiebre profundo en las tradiciones éticas de la política comunal" (Salazar-Pinto 1999:174). Y desde esta perspectiva la Reforma Educacional diseñada a partir de 1995, como política modernizadora neoliberal, rompe y fragmenta el concepto de identidad comunitaria, trabajando e estimulando su sensorialidad individual en desmedro de sus responsabilidades colectivas.

El Estado como agente público ha ido entregando a la empresa privada el manejo de la cultura, con lo cual la industria cultural ha aumentado los mercados pero también ha ido configurando espacios híbridos en las 
manifestaciones y en las identificaciones culturales, donde los culto-elitista se entrecruza con lo popularfolklórico. "En la medida en que disminuye el papel del poder público como garantía de la democratización informativa, de la socialización de bienes científicos y artísticos de interés colectivo, estos bienes dejan de ser accesibles para el resto. Cuando la cultura deja de ser asunto público, se privatiza la información y los recursos intelectuales en los que se apoya parcialmente la administración del poder. Y si el poder deja de ser público, puede restaurar parcialmente su verticalidad [...] Cuando estas transformaciones de fin de siglo implican democratización política y cultural, la oblicuidad que propician en el poder urbano y tecnológico se vuelve, más que dispersión pluralista, hermetismo y discriminación" (García 1995:348). En este sentido se va generando una fragmentación en la apropiación de los bienes simbólicos, al perder la cultura su espacio público de manifestación y de identificación, se genera una suerte de desmotivación y de no pertenencia al lugar.

El modelo económico neoliberal como ingrediente esencial de esta mundialización económica, política y cultural que se denomina globalización trae entre sus efectos más mediatos, debido a una ruptura con el pasado, una apatía política en los jóvenes. "El problema central del libremercadismo es su tendencia obsesiva a desvestir las identidades comunales nacionales y el carácter 'societal' de los sujetos. O sea: a extinguir, en los individuos, su carácter 'político', e incluso, su misma identidad de 'sujeto'. Es decir: todo lo que 'vista' al individuo con otro ropaje que no sea su cuerpo desnudo ante la expectativa de un festín sensorial. O imaginario. Tendencia que, sin duda, compromete la vigencia de los valores humanos de alcance estratégico" (Salazar-Pinto 1999:175). Lo que desde el punto de vista pedagógico atenta con los valores más recónditos del ser educativo, con la proyección del sí mismo al otro, construyendo a los individuos en sujetos, en personas partícipes e integrantes activas de una colectividad, donde la educación permite expandir las potencialidades de su ser en todos los planos (valórico, científico, técnico, y, en definitiva, humano). "Si la educación es el proceso por el cual se detecta y desarrolla el capital humano que hay en cada persona, una Reforma Educacional debe partir conociendo y respetando los matices de la identidad presentes en la cultura tradicional. Esto supone una escuela abierta a los valores de la comunidad, a la geografía y a la historia local” (Sepúlveda 2001:5).

Las actuales elites concertacionistas que comenzaron en forma pactada a gobernar a partir de 1989, no incidieron en forma significativa sobre el modelo neoliberal de carácter hegemónico, sumando la lógica hegemónica del neoliberalismo en sus proyectos coyunturales de modernización. Lo que en el área de la educación significo la modernización de la educación desde una teoría pedagógica constructivista, mediante la estructuración de nuevos planes y programas que planteaban una integración entre los aprendizajes conceptuales, los procedimentales y los actitudinales. Pero paradójicamente dentro de un contexto de la mercantilización de la educación, lo que implicaba la ausencia de un rol Docente por parte del Estado, asumiendo este desempeño el Mercado. Culturalmente la implantación de este modelo significo la reproducción de un espacio apático en la identificación cívica de los alumnos, personas y sujetos, ya que no trabaja desde la inclusión de un modelo multicultural haciendo partícipe, en la planificación pedagógica, a la sociedad civil, para lo cual se hace necesario la adopción de: “...un modelo educativo con vocación multicultural, y donde dicha vocación se refleje en contenidos, valores y prácticas pedagógicas. El respeto a la diversidad étnica y cultural, la educación cívica apoyada en la ciudadanía plena y extendida, la pertenencia curricular frente a distintas realidades sociales y culturales con que llegan lo niños a la escuela, así como el fomento a prácticas comunicativas basadas en el respeto al otro y la reciprocidad en la comprensión, son elementos básicos en este cambio de concepto" (Hopenhayn 2000:4). En definitiva la educación en Chile amerita la integración efectiva por parte del Estado, en donde se hagan efectivos los canales de participación de la sociedad civil, en pro de la construcción de un modelo pedagógico que coordine la modernización como estrategia de asimilación externa e interna con patrones culturales del ethos nacional. 


\section{Bibliografía}

Collier, Simon y Sater, William. 1996. Historia de Chile. 1808-1994. Ed. Cambridge University Press.

John Dewey. 1927 El niño y el programa escolar. Edición Castellana de la Revista de Pedagogía. En Labarca, Amanda: Nuevas Orientaciones de la Enseñanza.

García Canclini, Néstor. 1992. Culturas Híbridas. Ed. Sudamericana, Buenos Aires.

Hopenhayn, Martín. 2000. El reto de las identidades y la multiculturalidad. Barcelona, España.

Recio, Ximena. 2001. El discurso pedagógico de Pedro Aguirre Cerda. Serie monografías históricas $\mathrm{N}^{\circ}$ 10. Instituto de Historia, Universidad Católica de Valparaíso.

Salas, Darío. 1917. El Problema Nacional. Bases para la Reconstrucción de Nuestro Sistema Escolar Primario. Santiago.

Salazar, Gabriel y Pinto, Julio. 1999. Historia Contemporánea de Chile, Vols. I- II. Ed. Lom, Santiago.

Sepúlveda, Fidel. 2001. La Cultura Tradicional, Identidad, Globalización. En XVIII Temporada de Arte y Cultura Tradicional, Pontificia Universidad Católica de Chile, Santiago. 